\title{
Family planning in refugee settings: findings and actions from a multi-country study
}

\author{
Mihoko Tanabe ${ }^{1}$, Anna Myers $^{1 *}$ (D) Prem Bhandari ${ }^{2}$, Nadine Cornier ${ }^{3}$, Sathyanarayanan Doraiswamy ${ }^{3}$ \\ and Sandra Krause ${ }^{1}$
}

\begin{abstract}
Background: To address family planning for crisis-affected communities, in 2011 and 2012, the United Nations High Commissioner for Refugees and the Women's Refugee Commission undertook a multi-country assessment to document knowledge of family planning, beliefs and practices of refugees, and the state of service provision in the select refugee settings of Cox's Bazar, Bangladesh; Ali Addeh, Djibouti; Amman, Jordan; Eastleigh, Kenya; Kuala Lumpur, Malaysia; and Nakivale, Uganda.

Methods: The studies employed mixed methods: a household survey, facility assessments, in-depth interviews, and focus group discussions.

Results: Findings on awareness and demand for family planning, availability, accessibility, and quality of services showed that adult women aged 20-29 years were significantly more likely to be aware, to have ever used, or are currently using a modern method as compared to adolescent girls aged 15-19 years. Facility assessments showed limited availability of certain methods, especially long-acting and permanent methods. Despite availability, in all sites, focus group discussion participants_especially adolescents_-reported many accessibility-related barriers to using existing services, including distant service delivery points, cost of transport, lack of knowledge about different types of methods, misinformation and misconceptions, religious opposition, cultural factors, language barriers with providers, and provider biases.
\end{abstract}

Conclusion: Based on gaps, partners to the study developed short and long-term recommendations around improving service availability, accessibility, and quality. There remains a need to scale up support for refugees, particularly around adolescent access to family planning services.

Keywords: Family planning, Refugees, Conflict, Women of reproductive age, Adolescents, Access

\section{Background}

Previous studies around family planning in refugee situations show that published interventions for refugee communities have primarily focused on increasing access to care through supply side improvements, as well as shifting behaviors and attitudes to enhance demand and use [1,2]. The Inter-agency Working Group (IAWG) in Reproductive Health in Crises' 2012-2014 global review found the scarcity of long-acting and permanent methods, ${ }^{1}$ as well

\footnotetext{
* Correspondence: AnnaM@wrcommission.org

'Women's Refugee Commission, 15 W 37 Street, 9th Floor, New York, NY 10018, USA

Full list of author information is available at the end of the article
}

as other supply side challenges hindering accessibility [3]. Other studies have similarly documented challenges in supply chain management and provider biases that limit access to and uptake of family planning services in humanitarian settings $[1,4-6]$.

Studies examining the sexual and reproductive health (SRH) outcomes of refugees and internally displaced persons within camp settings compared to the host community present varying results, with both superior and inferior health outcomes between the two populations [7-10]. The results show that the diversity of populations and quality of services influence SRH outcomes. The ability to pay and distance to services are repeatedly cited as variables impacting use, as 
well as quality of services $[3,4,11,12]$. The IAWG global evaluation highlights the necessity for programs to integrate mechanisms to understand how to best address family planning needs in humanitarian settings [3].

To better understand barriers to contraceptive use and identify practical responses in refugee settings, in 2011 and 2012, the United Nations High Commissioner for Refugees (UNHCR) and the Women's Refugee Commission (WRC), with technical assistance from the U.S. Centers for Disease Control and Prevention (CDC), undertook a multi-country baseline study to document knowledge of family planning, beliefs and practices of refugees, as well as the state of service provision in the refugee settings of Cox's Bazar, Bangladesh; Ali Addeh, Djibouti; Amman, Jordan; Eastleigh, Kenya; Kuala Lumpur, Malaysia; and Nakivale, Uganda. The research examined the barriers and challenges at the community and health facility levels that hindered uptake of contraceptives, and the practical ways that the challenges could be addressed. This article summarizes key findings from the mixed-methods study, as well as some of the follow-up activities that were undertaken to address identified gaps.

\section{Methods}

Six countries were selected for data collection based on geographic diversity (Table 1). Specific locations within countries were chosen based on lack of family planning data; existence of a family planning program; refugees' previous exposure to family planning; and presumed cultural barriers. A family planning program was defined as a site that had a UNHCR-supported project that had a family planning component. Refugees' previous exposure to family planning implied whether the population could be assumed to receive some type of family planning information, either in their country of origin or site of refuge. The populations targeted lived in camps, settlements, and urban areas. The studies employed a multi-pronged approach: a household survey among women of reproductive age (WRA); facility assessments to examine service quality; in-depth interviews with community leaders; and focus group discussions with the refugee community (Table 2).
The study was commissioned by UNHCR Geneva for program improvement, and coordinated and supervised by the WRC. CDC provided technical assistance for quality assurance and assisted with data interpretation. The study supervisors were trained by the CDC and WRC before deploying to the field sites where they recruited and trained local teams on research ethics and data collection, and implemented the study. Study supervisors developed country-specific technical reports with detailed findings [13-19].

\section{Household survey}

A household survey based on family planning section of the CDC Reproductive Health Assessment Toolkit for Conflict-Affected Women was used to gather data on family planning-related knowledge, attitudes, and behavior among WRA [20]. Sampling frames for Cox's Bazar, Amman, and Kuala Lumpur were generated through UNCHR's ProGres database and registered mobile numbers. The remaining sites relied on spatial sampling.

Female interviewers were recruited from the host community. Female participants were asked to provide verbal consent and the surveys were administered in the refugees' dominant languages. No identifying characteristics of respondents were recorded during data collection. All collected data were entered by the study supervisors, cleaned, and analyzed using CSPro, SAS, or SPSS. For this article, the WRC and staff from the University of Michigan Institute for Social Research merged, cleaned, and re-analyzed the six country datasets using SPSS.

\section{Facility assessment}

Facility assessments were conducted to examine service availability, quality of services, and provider perspectives. Facilities were selected by UNHCR and its partners based on the level of care provided and included government- and UNHCR partner-run facilities. Broadly, facility assessments examined staffing, training, method mix, and capacity to meet infection prevention standards. The assessment was conducted using an adapted health facility checklist with a scoring grid; a short interview with providers (or staff in charge) in their primary language; and an observation of

Table 1 Data collection activities conducted

\begin{tabular}{|c|c|c|c|c|c|c|c|}
\hline Location & Setting & $\begin{array}{l}\text { Refugees' country } \\
\text { of origin }\end{array}$ & $\begin{array}{l}\text { \# of HH Survey } \\
\text { respondents }\end{array}$ & $\begin{array}{l}\text { \# of in-depth } \\
\text { interviews }\end{array}$ & $\begin{array}{l}\text { \# of FGD } \\
\text { participants }\end{array}$ & $\begin{array}{l}\text { \# of facilities } \\
\text { assessed }\end{array}$ & Study languages \\
\hline Ali Addeh, Djibouti & Camp & Somalia & 500 & 3 & 34 & 1 & Somali \\
\hline Eastleigh, Nairobi, Kenya & Urban & Somalia & 442 & 4 & 41 & 3 & Somali \\
\hline Nakivale, Uganda & Settlement & $\begin{array}{l}\text { Primarily } \\
\text { from DRC }\end{array}$ & 470 & 3 & 48 & 4 & $\begin{array}{l}\text { Swahili/Kinyarwanda/ } \\
\text { Somali and English }\end{array}$ \\
\hline Amman, Jordan & Urban & Iraq & 410 & 3 & 107 & 7 & Arabic \\
\hline Kuala Lumpur, Malaysia & Urban & Myanmar & 422 & 6 & 66 & 3 & Burmese \\
\hline Cox's Bazar, Bangladesh & Camp & Myanmar (Rohingya) & 507 & 4 & 30 & 4 & Burmese \\
\hline
\end{tabular}


Table 2 Focus Groups

\begin{tabular}{|c|c|c|c|c|}
\hline Location & $\begin{array}{l}\text { Women's Groups } \\
\text { (age 20-49 years) }\end{array}$ & $\begin{array}{l}\text { Men's Groups } \\
\text { (age 20-59 years) }\end{array}$ & $\begin{array}{l}\text { Adolescent Girls' Groups } \\
\text { (15-19 years) }\end{array}$ & $\begin{array}{l}\text { Adolescent Boys' Groups } \\
\text { (15-19 years) }\end{array}$ \\
\hline Cox's Bazar & Two groups: 8 women & One group & Two groups: 7 and 8 each & One group: 7 boys \\
\hline Ali Addeh & Two groups: $>28$ years & One group: $>40$ years & Two groups: $17-25$ years & One group: $19-25$ years \\
\hline Amman & $\begin{array}{l}\text { Three groups: averaging } 10 \\
\text { women/group; } 20-49 \text { years }\end{array}$ & $\begin{array}{l}\text { Three groups: averaging } 9 \\
\text { men/group }\end{array}$ & $\begin{array}{l}\text { Three groups: averaging } 9 \\
\text { girls/group; } 15-20 \text { years }\end{array}$ & $\begin{array}{l}\text { Three groups: averaging } 7 \\
\text { boys/group; } 15-21 \text { years }\end{array}$ \\
\hline Eastleigh & Two groups: Aged 22 and above & One group: Aged 22 and above & One group: Aged 16-22 & Two groups: Aged 16-22 \\
\hline Nakivale & Two groups: 8 women each & One group: 8 men & Two groups: 8 girls each & One group: 8 boys \\
\hline Kuala Lumpur & $\begin{array}{l}\text { Chin: One focus group, } 5 \text { women } \\
\text { Myanmar Muslims: } 6 \text { women }\end{array}$ & $\begin{array}{l}\text { Chin: } 4 \text { men } \\
\text { Myanmar Muslims: } 6 \text { men } \\
\text { Rohingya: } 6 \text { men }\end{array}$ & $\begin{array}{l}\text { Chin: } 8 \text { girls } \\
\text { Myanmar Muslims: } 7 \text { girls } \\
\text { Rohingya: } 6 \text { girls }\end{array}$ & $\begin{array}{l}\text { Chin: } 8 \text { boys } \\
\text { Myanmar Muslims: } 5 \text { boys } \\
\text { Rohingya: } 3 \text { boys }\end{array}$ \\
\hline
\end{tabular}

family planning consultations. Study supervisors entered the data into an Excel database for analysis.

\section{In-depth interviews}

In-depth interviews were conducted among men and women and included refugee community leaders, imams, and health volunteers. The guides were developed by WRC and UNHCR and translated and reviewed in each site. The interviews were conducted in the local language through an interpreter. The questions sought to learn about challenges and barriers to increasing contraceptive uptake within the refugee community. Respondents were purposively selected by UNHCR and partners based on interviewees' presumed knowledge of the community and/ or their constituents if they were leaders.

\section{Focus group discussions (FGDs)}

FGDs were held with refugee women, men, adolescent girls, and adolescent boys to gather qualitative data on attitudes towards and barriers to contraceptive uptake. The FGDs were conducted in the local languages by a facilitator of the same gender of the group, and audio recorded. The study supervisors transcribed, translated, and analyzed the data per site.

\section{Results}

\section{Respondents and health facilities}

All health facilities assessed were supported by UNHCR, and included government referral hospitals and NGO clinics. In Amman, Eastleigh, and Kuala Lumpur, both government and NGO health facilities were assessed. In Cox's Bazar, Ali Addeh, and Nakivale, facilities were run by national and international NGOs.

\section{Quantitative analysis}

For quantitative analysis, responses from 2,733 refugee women were included. We used four outcome measures: awareness, ever use, current use, and unmet need for family planning methods. All of these outcomes are measured as a dichotomy, yes (coded 1) versus no (coded 0). Our explanatory measures were women's age, marital status, education, and location of refuge as a respondent's background characteristics. Age and marital status are important proximate determinants of fertility, and hence, for contraceptive use [21-24]. Similarly, education is one of the determinants of contraceptive awareness, use, and unmet need [25-29]. Thus, we explored whether there was any association between these background characteristics and outcomes. We also controlled for site of refuge as the association between explanatory and outcome measures.

First, we describe the sample using simple descriptive tools such as frequencies and percentages. Second, we examine associations between various outcome measures by women's background measures (Table 3). We then provide distribution of outcome measures of each modern and traditional method by women's background characteristics (Table 4). Finally, as the bi-variate results may mislead conclusions due to confounding from other factors, we use multivariate analysis to explain the net effects of various background characteristics on outcomes of interest. As all four outcome measures are dichotomous in nature, we used binary logistic regression as the multivariate tool. Results are provided in Table 5 and described below.

\section{Awareness and demand}

We examined associations between women's background characteristics such as age, marital status, education, and site of refuge on awareness, ever use, current use, and unmet need in the six settings. The analysis includes information from 2,733 women (excludes 10 missing for age and school attendance). ${ }^{2}$

\section{Awareness of any modern method}

Overall, 74\% of surveyed WRA reported that they were aware of at least one modern method of family planning (Table 3).

The associations between women's awareness of modern family planning methods and age, marital status, education, and site of refuge are provided in Table 4 below.

The results show that women's awareness to at least one modern method varied by age, marital status, education, and site of refuge. Adolescent girls (15-19 years) were significantly less aware of any modern method compared to 
Table 3 Descriptive statistics of measures used in the analysis $(n=2733)$

\begin{tabular}{|c|c|c|c|c|}
\hline \multirow[t]{2}{*}{ Measures } & \multicolumn{4}{|c|}{ Outcome measures } \\
\hline & $\begin{array}{l}\text { Awareness } \\
\mathrm{n}(\%)\end{array}$ & $\begin{array}{l}\text { Ever use } \\
\mathrm{n}(\%)\end{array}$ & $\begin{array}{l}\text { Current use } \\
\mathrm{n}(\%)\end{array}$ & $\begin{array}{l}\text { Unmet need } \\
\text { n (\%) }\end{array}$ \\
\hline Outcome measures (Yes) & $2021(73.9)$ & $1059(38.7)$ & $543(19.9)$ & $184(6.7)$ \\
\hline \multicolumn{5}{|l|}{ Explanatory measures } \\
\hline \multicolumn{5}{|l|}{ Age } \\
\hline $\begin{array}{l}15-19 \text { years } \\
20-49 \text { years }\end{array}$ & $\begin{array}{l}192(55.2)^{* * *} \\
1829(76.7)\end{array}$ & $\begin{array}{l}35(10.1)^{* * *} \\
1024(42.9)\end{array}$ & $\begin{array}{l}14(4.0)^{* * *} \\
529(22.2)\end{array}$ & $\begin{array}{l}14(4.0)^{*} \\
170(7.1)\end{array}$ \\
\hline \multicolumn{5}{|l|}{ Current marital status } \\
\hline $\begin{array}{l}\text { Married } \\
\text { Unmarried (Other) } \\
\text { Missing response }\end{array}$ & $\begin{array}{l}1524(76.8)^{* * * *} \\
299(64.9) \\
198(69.0)\end{array}$ & $\begin{array}{l}953(48.0)^{* * *} \\
74(16.1) \\
32(11.1)\end{array}$ & $\begin{array}{l}522(26.3)^{* * *} \\
15(3.3) \\
6(2.1)\end{array}$ & $\begin{array}{l}174(8.8)^{* * * *} \\
7(1.5) \\
3(1.0)\end{array}$ \\
\hline \multicolumn{5}{|l|}{ Education } \\
\hline $\begin{array}{l}\text { Ever attended } \\
\text { Never attended }\end{array}$ & $\begin{array}{l}1162(83.8)^{* * *} \\
859(63.8)\end{array}$ & $\begin{array}{l}604(43.6)^{* * *} \\
455(33.8)\end{array}$ & $\begin{array}{l}319(23.0)^{* * *} \\
224(16.6)\end{array}$ & $\begin{array}{l}80(5.8)^{*} \\
104(7.7)\end{array}$ \\
\hline \multicolumn{5}{|l|}{ Site of refuge } \\
\hline $\begin{array}{l}\text { Ali Addeh } \\
\text { Eastleigh } \\
\text { Nakivale } \\
\text { Amman } \\
\text { Kuala Lumpur } \\
\text { Cox's Bazar }\end{array}$ & $\begin{array}{l}178(35.6)^{* * *} \\
256(16.1) \\
376(81.2) \\
383(94.1) \\
373(89.9) \\
455(89.7)\end{array}$ & $\begin{array}{l}48(9.6)^{* * *} \\
62(14.1) \\
56(15.7) \\
132(34.9) \\
123(39.4) \\
231(48.5)\end{array}$ & $\begin{array}{l}20(4.0)^{* * *} \\
36(8.2) \\
68(14.7) \\
98(24.1) \\
134(32.3) \\
187(36.9)\end{array}$ & $\begin{array}{l}8(1.6)^{* * *} \\
17(3.9) \\
79(17.1) \\
20(4.9) \\
32(7.7) \\
28(5.5)\end{array}$ \\
\hline
\end{tabular}

Chi-square $+\mathrm{p}<.10,{ }^{*} p<.05,{ }^{* *} p<.01,{ }^{* * *} p<.001$

adult women (20-49 years); $76.7 \%$ of adults reported that they were aware of any modern method, and $55.2 \%$ of adolescents were aware of any modern method. Further, $76.8 \%$ of married women reported that they were aware of any modern method compared to $64.9 \%$ of unmarried women. Women who ever attended school were more likely to report that they were aware of any modern method compared to those who never attended school.

By site of refuge, $94.1 \%$ of women in Amman were aware of any modern method, followed by Kuala Lumpur (89.9\%), Cox's Bazar (89.7\%), and Nakivale (81.2\%). In Ali Addeh and Eastleigh, 35.6\% and 16.1\% of women reported they were aware of any modern method, respectively. Associations were also found between awareness and individual background characteristics (Table 4).

By method, most women were aware of oral contraceptive pills (66.7\%), followed by male condoms $(56.7 \%)$ and injectables (49.8\%). However, awareness of each method varied by site (Table 4$)$.

Multivariate results show that adolescents were $72 \%$ (odds ratio $=0.276 ; p<.001$; Table 5 ) less likely to be aware of any modern method compared to adults, controlling for marital status, school attendance, and site of refuge. Net of other factors, married women were two times (odds ratio $=2.080$; $p<.001)$ more likely to be aware of any modern method, compared to other women who were not currently married. Similarly, women who ever attended school were nearly three times (odds ratio $=2.760 ; p<.001$ ) more likely to be aware of any modern method compared to those who never attended school.
Site of refuge and awareness of any modern method were statistically significant: Adjusting for other factors, women living in Ali Addeh were nearly 95\% (odds ratio = 0.046; $p<.001$; Table 5) less likely to be aware of any modern method compared to their counterparts living in Cox's Bazar. Similarly, those living in Eastleigh, Nakivale, and Kuala Lumpur were $89 \%, 60 \%$, and $49 \%$ less likely to be aware, respectively, compared to women in Cox's Bazar, controlling for other factors.

\section{Ever use of any modern method}

Among the women surveyed, 38.7\% reported that they ever used any modern method of family planning (Table 3 ). These results also suggest that adolescents were significantly less likely to report ever use of any modern method compared to older women. Among adolescents, 10.1\% reported that they ever used any modern method compared to $42.9 \%$ of adults. More married women (48.0\%) were likely to report ever use of modern contraceptives compared to other (unmarried) women (16.1\%). Significantly greater proportions $(43.6 \%)$ of women who ever attended school reported that they ever used any modern method compared to $33.8 \%$ among those who never attended school.

By site of refuge, significantly greater proportions (48.5\%) of women in Cox's Bazar reported ever use of any modern method compared to women in other sites. In contrast, a small proportion (9.6\%) of women from Ali Addeh reported that they ever used any modern method. Ever use of specific modern and traditional methods by age, marital status, school attendance, and site of refuge are provided in Table 4. 
Table 4 Awareness, ever use, and current use of family planning methods by women's background characteristics and site of refuge

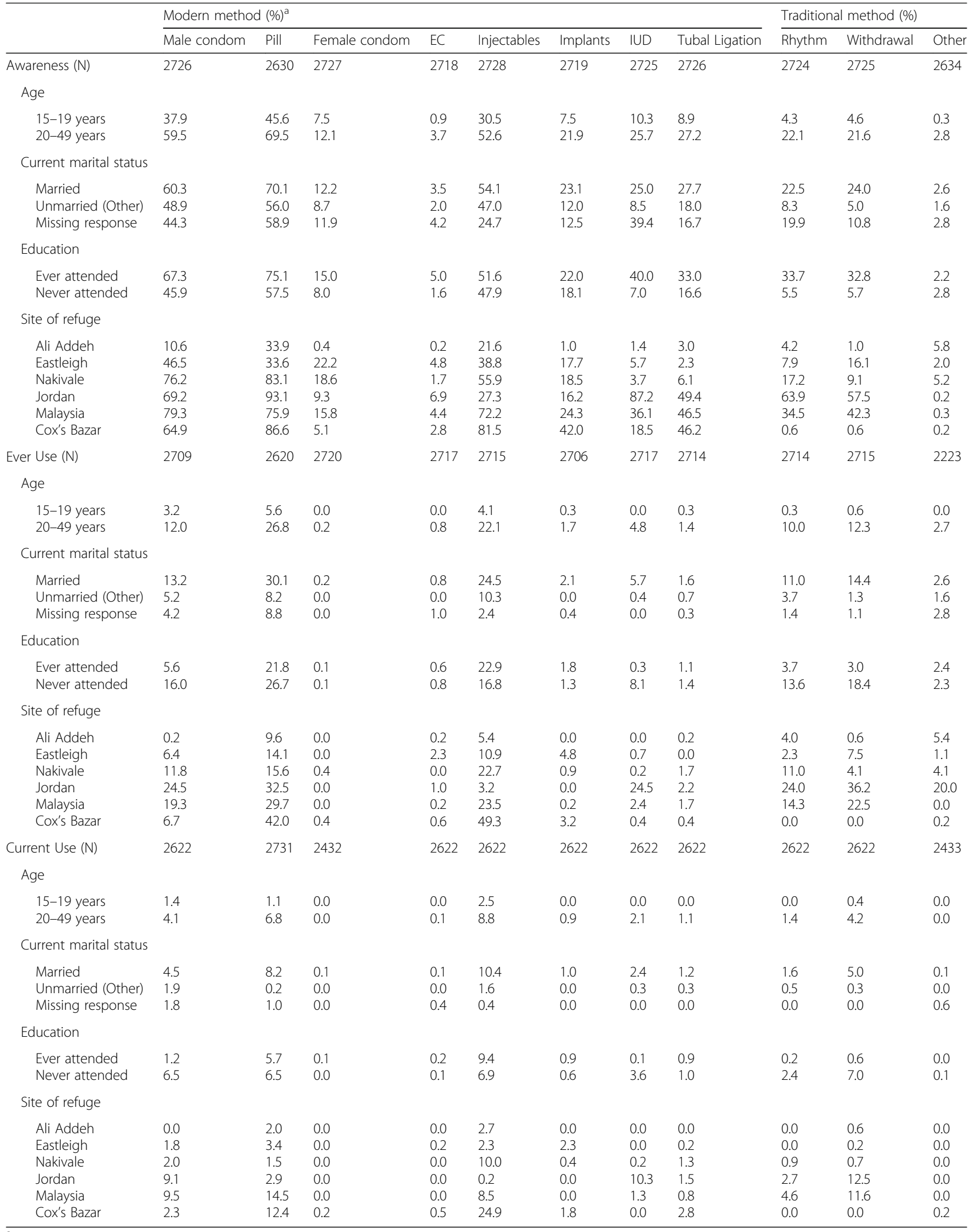

${ }^{\mathrm{a}}$ Per CDC's RH Assessment Toolkit, vasectomy has been excluded from the information on awareness, current use, ever use, and unmet need. It was not collected from the refugee women in this survey 
Table 5 Binary logistic regression (odds ratios in parenthesis) results estimating awareness, ever use, current use, and unmet need for family planning by women's background characteristics and site of refuge

\begin{tabular}{|c|c|c|c|c|}
\hline \multirow[t]{2}{*}{ Explanatory Measures } & \multicolumn{4}{|c|}{ Outcome measures } \\
\hline & Awareness & Ever use & Current use & Unmet need \\
\hline \multicolumn{5}{|l|}{ Age (Ref: 20-49 years) } \\
\hline $15-19$ years & $-1.287(0.28)^{* * *}$ & $-1.573(0.21)^{* * *}$ & $-1.118(0.33)^{* * *}$ & $0.331(1.39)$ \\
\hline \multicolumn{5}{|l|}{ Marital Status (Ref: Not married) } \\
\hline $\begin{array}{l}\text { Married } \\
\text { Missing information }\end{array}$ & $\begin{array}{l}0.733(2.08)^{* * *} \\
0.304(1.36)\end{array}$ & $\begin{array}{l}1.730(5.64)^{* * *} \\
-0.496(0.61)+\end{array}$ & $\begin{array}{l}2.598(13.44)^{* * *} \\
0.008(1.01)\end{array}$ & $\begin{array}{l}1.972(7.19)^{* * * *} \\
0.069(1.07)\end{array}$ \\
\hline \multicolumn{5}{|l|}{ Education (Ref: Never attended) } \\
\hline Ever attended & $1.015(2.76)^{* * *}$ & $0.688(1.99)^{* * *}$ & $0.688(1.99)^{* * *}$ & $-0.285(0.75)$ \\
\hline \multicolumn{5}{|l|}{ Site of refuge (Ref: Cox's Bazar) } \\
\hline Ali Addeh & $-3.072(0.05)^{* * *}$ & $-2.994(0.05)^{* * *}$ & $-2.899(0.06)^{* * *}$ & $-1.292(0.28)^{* *}$ \\
\hline Eastleigh & $-2.161(0.12)^{* * *}$ & $-2.248(0.11)^{* * *}$ & $-2.150(0.12)^{* * *}$ & $-0.316(0.73)$ \\
\hline Nakivale & $-0.931(0.39)^{* * *}$ & $-1.819(0.16)^{* * *}$ & $-1.600(0.20)^{* * *}$ & $1.227(3.41)^{* * *}$ \\
\hline Amman & $-0.249(0.78)$ & $-0.819(0.44)^{* * *}$ & $-1.115(0.50)^{* * *}$ & $0.227(1.26)$ \\
\hline Kuala Lumpur & $-0.673(0.51)^{* *}$ & $-1.262(0.28)^{* * *}$ & $-0.690(0.50)^{* * *}$ & $0.623(1.87)^{* * *}$ \\
\hline \multicolumn{5}{|l|}{ Model Fit Statistics } \\
\hline$N$ & 2733 & 2733 & 2733 & 2733 \\
\hline Intercept & $1.730(5.64)^{* * *}$ & $-0.545(0.58)^{* * *}$ & $-2.740(0.07)^{* * *}$ & $-4.513(0.01)^{* * *}$ \\
\hline -2 Log Likelihood & 2320.80 & 2757.02 & 2124.31 & 1193.12 \\
\hline Cox \& Snell R Square (\%) & 25.8 & 27.9 & 19.7 & 5.5 \\
\hline Nagelkerke R Square (\%) & 37.8 & 37.8 & 31.3 & 14.2 \\
\hline Percent correctly classified (\%) & 79.5 & 77.8 & 80.2 & 93.3 \\
\hline Model $X^{2}$ & $814.49^{* * *}$ & $892.14^{* * *}$ & $600.88^{* * *}$ & $155.16^{* * *}$ \\
\hline d.f. & 9 & 9 & 9 & 9 \\
\hline
\end{tabular}

$+p<.10 ;{ }^{*} p<.05 ;{ }^{* *} p<.01 ; * * * 0<.001$

By method, one-fourth of women (24.2\%) reported ever using the pill. This was followed by injectables (19.8\%), male condoms $(10.9 \%)$, and withdrawal $(10.8 \%)$; a traditional method. Ever use of specific methods also varied by site. While $49.3 \%$ of women in Cox's Bazar reported that they ever used injectables, $42.0 \%$ reported that they ever used the pill. These methods were less common in other sites including Ali Addeh and Amman. Similarly, ever use of other methods also varied by site.

Multivariate results show adolescents were $79.3 \%$ (odds ratio $=0.207 ; p<.001$ ) less likely to report ever use of any modern method compared to adult women, net of other factors (Table 5). Married women were nearly six times (odds ratio $=5.641 ; p<.001$ ) more likely to report ever use of any modern method compared to women who were not currently married. Women who ever attended school were nearly two times (odds ratio $=1.990 ; p<.001$ ) more likely to report ever use of any modern method compared to women who never attended school.

\section{Current use of any modern method}

Altogether, one in five women (19.9\%) reported that they were currently using any modern method (Table 3).
Bivariate results suggest that more adult women (22.2\%) were currently using any modern method compared to $4.0 \%$ of adolescents. Significantly greater proportions of married women $(26.2 \%)$ were currently using any modern method to avoid or delay pregnancy compared to other currently unmarried women. As expected, women who attended school were significantly more likely to report current use of any modern method. The distribution of current use of modern and traditional methods is provided in Table 4.

Among women reporting current use of any modern method, $8.1 \%$ of women were currently using injectables followed by pills (6.1\%), male condoms (3.9\%), and withdrawal (3.8\%). Current use of specific methods also varied by site.

Results in Table 5 suggest that adolescents were significantly less likely (odds ratio $=0.327 ; p<.001$ ) to report current use of any modern method compared to adults, adjusting for all other factors. Married women were more than 13 times (odds ratio $=13.438 ; p<.001$ ) more likely to currently use any modern method compared to currently not married women, controlling for all other factors. Similarly, net of other factors, women who ever attended school were two times (odds ratio $=1.990 ; p<.001$ ) more likely to report current use of any modern method 
compared to women who never attended school. By site of refuge, women living in all other sites were significantly less likely to report current use of any modern contraceptives compared to those living in Cox's Bazar.

\section{Unmet need for family planning}

We examined unmet need ${ }^{3}$ for family planning among women in the six refugee settings. Overall, $6.7 \%$ of women reported unmet need for family planning. These are women who reported not wanting more children and are currently not using any modern method to stop or delay pregnancy.

From Table 3, $4 \%$ of adolescents compared to $7.1 \%$ adults reported unmet need for family planning. Similarly, $8.8 \%$ of currently married women reported an unmet need compared to $1.5 \%$ of currently not married women. A greater proportion $(7.7 \%)$ of women who never attended school reported an unmet need compared to $5.8 \%$ of those who ever attended school. This scenario also varied by site.

Results from multivariate analyses suggest that only marital status and site of refuge remained significant for unmet need. Married women were slightly over seven times (odds ratio $=7.192 ; p<.001$ ) more likely to report unmet need compared to those who were not currently married, net of other factors. By site of refuge, women living in Ali Addeh were significantly less likely to report unmet need.

\section{Availability of family planning services}

Facility assessments showed limited availability of certain methods. In Ali Addeh, Eastleigh, Kuala Lumpur, and Cox's Bazar, all assessed facilities were offering at least three short-term methods (primarily male condoms, pills, and injectables); assessed facilities in Nakivale and Amman were not (Table 6).

Stock outs of oral contraceptives were reported in Nakivale and Ali Addeh, the latter stemming from shortages at the regional level. In Amman, UNHCR's two partners were not providing any family planning method, one citing religious reasons. However, the Ministry of Health $(\mathrm{MoH})$ was providing free contraceptives to Iraqi refugees and encouraging them to access public services. Three public health facilities and one private NGO clinic provided more than three short-term methods. In Ali Addeh, Amman, and Kuala Lumpur, inadequate numbers of service centers or staff providing family planning were also barriers to availability.

Findings varied in terms of availability of long-acting and permanent methods (Table 6). In Eastleigh, all three visited facilities were offering implants and the intrauterine device (IUD), and two of three performed tubal ligation and vasectomy. In Amman, UNHCR's partners did not provide any such methods; no assessed facility in Ali Addeh and Nakivale provided these methods.

In terms of emergency contraception (EC), only Ali Addeh and Eastleigh had the commodity available in all assessed facilities. In Amman, a prescription was necessary to obtain EC from pharmacies and UNHCR partner facilities. In all contexts where EC was available, it was primarily in the context of clinical care for survivors of sexual assault and not as a part of family planning programs (Table 6).

Community reports of contraceptive availability also differed by setting. In Ali Addeh, Kuala Lumpur, and Cox's Bazar, FGD participants reported that they could obtain contraceptives from government facilities and/or NGO clinics. In Kuala Lumpur and Cox's Bazar, participants reported accessing contraceptives from community health workers (CHWs). However, in reality, many Burmese refugees in Kuala Lumpur reported purchasing contraceptives-especially oral contraceptives-in pharmacies, or illegally, from Burmese shops. Similarly in Amman, while contraceptives were available and free at public health facilities, many Iraqis reportedly obtained them at pharmacies. In Nakivale, despite partner efforts to maintain roughly 25 condom dispensers in the settlement, adolescent girls who exchanged sex for money reported frequently finding them empty.

\section{Accessibility of family planning services}

Despite availability of some methods, in all sites, FGD participants reported many accessibility-related barriers to using family planning services. Common challenges included: Distant service delivery points (Nakivale, Kuala Lumpur); cost of transport to access services (Amman, Kuala Lumpur); lack of knowledge about different types of methods, especially EC (all sites); misinformation and misconceptions (Ali Addeh, Eastleigh, Nakivale, Kuala Lumpur); religious opposition (all but Amman); cultural factors or social stigma (Ali Addeh, Nakivale, Cox's

Table 6 Summary of facility assessments

\begin{tabular}{llllllc}
\hline & Ali Addeh & Eastleigh & Nakivale & Amman & Kuala Lumpur & Cox's Bazar \\
\hline Facilities offering at least three short-term methods & 1 & 3 & 3 & 4 & 3 & 4 \\
Facilities offering at least one long-acting method & 0 & 3 & 0 & 4 & 1 & 1 \\
Facilities offering at least one permanent method & 0 & 2 & 0 & 1 & 0 & 0 \\
Facilities offering EC & 1 & 3 & 3 & 2 & 0 \\
Facilities offering EC in context of family planning program & 0 & 0 & 0 & 0 & 0 \\
\hline
\end{tabular}


Bazar); language barriers with providers (Eastleigh, Kuala Lumpur); opposition from husbands (Eastleigh, Cox's Bazar); and provider biases (Ali Addeh, Eastleigh, Nakivale, Amman). Provider biases included discrimination against refugees (Iraqis in Amman; Somalis in Eastleigh). A Somali woman explained, "Somalis in Kenya are treated like second-class citizens. When you go to the hospital, they are not nice. The doctors and nurses should be friendly to the Somali people... These people, they do not know how to talk to somebody. They make the Somali people to feel very low."

In Kuala Lumpur, costs of services, transport, and concerns of being detained-especially for unregistered refugees-were major barriers in refugees' ability to seek services. Misinformation that was raised among the Burmese in Kuala Lumpur and Congolese in Nakivale was that modern methods can cause birth defects in future children and infertility in women after cessation.

Participants also reported that they were aware of the benefits of planning families despite limited information, education, and communication (IEC) materials and varying degrees of opposition to use. In terms of religious-based resistance, among the Somalis in Eastleigh and Ali Addeh; the Muslim and Christian Burmese in Kuala Lumpur; and the Muslim, Catholic, and Pentecostal communities in Nakivale; religious teaching was cited as a major factor discouraging the use of modern methods. Somalis in Eastleigh, however, noted that exclusive breastfeeding and other natural methods of child spacing were, in fact, encouraged by religion. The Burmese acknowledged that their religion allowed for the use of contraceptives to protect the health of the mother and to adapt to the challenges of displacement. Religion was not reported as a major barrier by Iraqis in Amman, and in Cox's Bazar, religious leaders were supportive of the concept of planning families. In fact, in Cox's Bazar, FGD participants acknowledged decreasing resistance to family planning in the community.

In all sites, adolescents reported difficulty accessing services, as premarital sex is disapproved of, particularly among Iraqis, the Burmese, Rohingya, and Somalis. As one adolescent boy reported in Cox's Bazar, "Even if the service would be offered from the camp clinic, they would not go considering the risk that the community might get informed, noticing them going to the family planning clinic."

In Nakivale, adolescents were hesitant to seek contraceptives from the health facility, as family planning consultations took place in the maternity ward. While gender-based violence programs offered EC to survivors of sexual assault, family planning providers, especially in Nakivale, reportedly disapproved of making EC available for non-sexual assault cases, citing that it could promote promiscuity. In Cox's Bazar, facility assessments revealed that unmarried adolescents could not receive contraceptives from the camp clinics since commodity distribution is reported to the government. They could only receive condoms through the camp HIV programs.

\section{Quality of available services}

When asked about available family planning services in FGDs, women-with the exception of those in Cox's Bazar-noted issues pertaining to the lack of adherence to standard precautions, lack of cleanliness, long wait times, limited options for privacy, and lack of confidentiality as factors that impacted their willingness to obtain contraceptives from health facilities. In Amman, women reported accessing contraceptives from pharmacies rather than for free from public health facilities due to long wait times and unhygienic practices. Likewise in Eastleigh, the lack of privacy and long wait times in public facilities drove women to private clinics. In Nakivale, consultation times were inconvenient for women undertaking domestic chores and too short for adequate counseling. Hours were also not conducive to client needs, leading women to seek services at pharmacies and private health facilities.

Facility assessments also attested to varied levels of quality across facilities and settings. In terms of the challenges reported by FGD participants, on average, facilities in Kuala Lumpur and Ali Addeh showed better adherence to infection prevention standards, while those in Eastleigh fared worse. Facility assessments further showed that in Amman, the government referral clinics were overcrowded. However, most facilities demonstrated strong capacity to meet infection prevention standards. In Eastleigh, the assessed public facility reported more challenges with longer wait times and lack of adequate privacy compared to the two private facilities. In Cox's Bazar, higher standards of privacy and confidentiality were observed in camp clinics compared to government clinics. In Ali Addeh, facility staff reported that wait times for consultations were hours, and the distance from the health center to the farthest parts of the camp was two kilometers.

Facility assessments also examined the strength of the referral system. A system existed in Eastleigh to provide clients with referrals for contraception; however, referrals were not followed-up. Whereas in Cox's Bazar, among facilities that were not providing certain long-acting or permanent methods, referrals from the camp clinics were relatively strong. Follow-up was better reported among camp clinics compared to government clinics. Community volunteers were also responsible for individual follow-up through home visits. In Amman, where UNHCR's partners did not offer any contraceptives, one of the two facilities provided educational materials and information about facilities that provided family planning. In Ali 
Addeh and Nakivale, where no assessed facility provided any long-acting or permanent methods, no functioning referral system was in place.

In terms of staffing, the assessed facilities in Eastleigh had adequate staff to provide family planning services. In Cox's Bazar, Kuala Lumpur, and Nakivale, high caseloads were observed, leading to consultations that were too short in duration for informed decision-making and limited privacy. A government clinic in Kuala Lumpur, favored by the Burmese refugees for perceived quality and access to interpretaters, was reportedly stretched, with providers alluding to the need for refresher trainings. In Nakivale, midwives were particularly overstretched since they dealt with antenatal care, post-natal care, family planning, and deliveries. All providers in Nakivale reported gaps in their skills and requested refresher trainings, as well as trainings on long-acting methods and new contraceptive technologies. Among public facilities providing family planning in Amman, staff had received extensive training in modern methods. Nevertheless, the need for routine refresher trainings was observed in all sites. In Ali Addeh, the midwife provided family planning services and counseling, and expressed the need for follow-up training. The staff reported the facility's ability to provide comprehensive family planning services to the community to be at $30 \%$.

\section{Discussion}

\section{Awareness and demand}

The household study findings show that awareness, ever use, current use, and unmet need for family planning varied by age, marital status, school attendance, and site of refuge. Regarding awareness, ever use, and current use, adult women aged 20-49 years were significantly more likely to be aware, to have ever used, or are currently using a modern method as compared to adolescent girls aged 15-19 years, net of other factors. Similar differences were also found between married women and women who were currently not married. As demonstrated in other studies, education played a large role in awareness, ever use, and current use: women who attended some level of schooling were at least twice as likely to be aware, have ever used, or were currently using a modern method [25-29].

In terms of contributions towards awareness, FGD participants reported receiving family planning information from home visits as an appropriate and wellreceived channel (Amman). Participants in other settings identified the most appropriate avenues to receive information through CHWs, family planning field workers, NGOs, leaders from the community, women's organizations (Ali Addeh), and religious leaders (Eastleigh). In Nakivale, RH sessions (without contraceptive distribution) reportedly took place after school.
Marital status was the only individual background factor that influenced unmet need. Married women were more likely to report unmet need compared to those who were not currently married, based on how this indicator was defined.

In terms of site of refuge, due to the types of existing programs, it is not surprising that women in Cox's Bazar reported significantly higher current use of modern methods as compared to women in the other five settings, controlling for age, marital status, and education. Unmet need was reportedly high in Nakivale where the qualitative methods used in this study showed limited accessibility, although the household survey did not find significant differences in unmet need by age and education.

\section{Improving availability, accessibility, and quality}

Since the purpose of the assessment was to improve programming, UNHCR, WRC, and partners developed shortand longer-term recommendations based on the findings that have been summarized in country-specific, selfpublished reports [13-19]. Recommendations in particular focused on ensuring availability of long-acting methods-which has been documented to be increasingly acceptable and feasible in humanitarian settings, including among the populations encompassed in the study-and EC to enhance method mix $[4,30]$. They further focused on increasing accessibility of contraceptives for adolescents; as well as making service quality improvements around adherence to standard precautions, cleanliness, wait times, and privacy; strengthening mechanisms for follow-up; and addressing staffing challenges. Recommendations were based on documented good practices and existing guidance, taking into account feasibility, as well as priority concerns as shared by the communities [31]. Countries addressed gaps by integrating some or all of the setting-specific recommendations into country work plans. In 2015, UNHCR and the WRC followed-up on the implementation of recommendations, through a self-reported questionnaire to UNHCR country offices delivered and received via email. Five of six countries responded (all but Kenya), with the most progress reported in Djibouti, which has prioritized family planning. While the settings represented different displacement contexts-camps, settlements, and urban areas-many of the activities undertaken appeared similar due to common challenges.

\section{Improving availability}

To improve contraceptive availability, countries have primarily focused on increasing the number of service delivery points providing family planning methods; increasing the number of trained providers; improving method mix; and/ or actively addressing contraceptive security [31]. The $\mathrm{MoH}$ in Jordan has authorized trained midwives to insert IUDs in $\mathrm{MoH}$ facilities, which is a substantial change from 
the time of the assessment when only physicians were permitted to provide this service. Further, as a result of updates in 2015 to the Jordanian MoH's RH policies, all static clinics run by UNHCR partners and $\mathrm{MoH}$ facilities are providing a more enhanced method mix. In Ali Addeh, a midwife and medical doctor have been trained to insert implants and IUDs, and EC has been made available in the camp beyond post-rape care. The camp-based family planning program has also been integrated with the national family planning program, and UNHCR is working closely with the $\mathrm{MoH}$ and UNFPA to source supplies and actively prevent shortages. In Nakivale, contraceptive security has been improved with supplies from UNFPA, and UNHCR is piloting CHW distribution of Sayana Press in the Kyaka II refugee settlement. The country office is further referring clients to Marie Stopes and Reproductive Health Uganda for long-acting and permanent methods, to complement the static services provided by midwives.

\section{Improving accessibility}

To improve accessibility, most country offices reported focusing heavily on community outreach strategies, a critical component of a successful family planning program [31]. The Uganda country office's outreach included billboards on the benefits of family planning, training of CHWs, and dissemination of job aids. In Ali Addeh, in partnership with CARE USA, 190 refugee youth were trained in family planning-including for EC-and youth clubs were established in each camp. Partners in Cox's Bazar disseminated family planning information through "adolescent corners" in the camps. UNHCR Malaysia, however, reported that funding cuts have reduced the number of employed $\mathrm{CHWs}$, which has limited outreach activities and attempts to address other reported challenges, such as transport costs in the urban setting. The Uganda office too, has had to move from paid CHWs to voluntary Village Health Teams, who have received fewer training opportunities. Both countries report the continued need to strengthen $\mathrm{SRH}$ services for adolescents.

\section{Improving quality}

Overall, country offices have reported improving service quality through staff training, routine monitoring and supervision, refurbishments to facilities (including to improve cleanliness and address privacy), and strengthening referral mechanisms. Such inputs are encompassed under existing guidance for family planning programming in humanitarian settings [31]. In Ali Addeh, UNHCR focused on facility-based improvements, and health facilities have addressed long wait times and limited privacy by establishing a family planning consultation room. Individual files have been created for client follow-up, and the $\mathrm{MoH}$ and UNHCR's partners have instituted quarterly supervision. Similarly in Amman, UNHCR has conducted routine monitoring visits for quality control; bi-annual health access and utilization surveys and FGDs with refugees are addressing client satisfaction. Electronic information management has improved referrals and reportedly reduced wait times. In Cox's Bazar, quality is being monitored by partners. UNHCR Uganda has developed a family planning service referral form to strengthen referrals to other SRH services.

\section{Limitations}

Limitations to the study include insufficient time, as not all teams were able to implement the suggested 12 FGDs or visit all tertiary level facilities accessed by refugees. Sampling posed challenges, especially in urban settings, due to limited accuracy of registration lists and recorded cell phone numbers. The self-reported nature of the survey is a limitation; the survey also did not capture method switching and discontinuation. A lack of privacy and the sensitive nature of the topic may have created reporting bias in the survey, especially in Cox's Bazar, Eastleigh, and Nakivale. Social desirability bias of respondents, particularly among unmarried women and adolescent girls, was perceived to exist, especially in Amman, Ali Addeh, and Eastleigh.

\section{Conclusion}

This article describes findings from a six setting family planning study, as well as actions that were implemented in each setting based on the findings. Political will within UNHCR offices was a major factor enabling their ability to respond to recommendations. On the contrary, lack of funding reduced the capacity of UNHCR offices to fully respond to recommendations. While a similar study is necessary to examine true change at the population level and to further add to the literature, some positive reflections have been observed from this research to action process [32]. These include the importance of stakeholder trainings, as well as engaging community members and religious leaders. Cox's Bazar has had marked success around engaging religious leaders to serve as proponents of family planning. Across country offices, the importance of training, monitoring, and supervision have been emphasized for staff, $\mathrm{CHWs}$, youth, and community leaders. Indeed, a recent study by Curry et al. reports that through competency-based training, supply chain management, systematic supervision, and community mobilization to raise awareness and shift norms in crisis-affected Chad, Democratic Republic of the Congo (DRC), Djibouti, Mali, and Pakistan, CARE's projects have managed to increase uptake of long-acting methods in particular [33]. Other reported learning include the benefits of a coordinated approach with UNFPA who addresses SRH, as well as designating a focal point to be responsible for contraceptive security.

Globally there remains a continued need to scale up family planning services in humanitarian settings from 
acute emergency through protracted crises and development. In the wake of global commitments to enhance access to SRH-including family planning for all-it is important to examine the state of programming, identify and respond to gaps, and see through recommendations. Much has been documented that recognizes that family planning needs to be available during an emergency and through protracted displacement, to reduce unintended pregnancy and its consequences [31]. The right to SRH and family planning is not lost in crises, and this must be recognized in the current waves of migration and displacement that span countries and regions.

\section{Endnotes}

${ }^{1}$ Short-acting methods include male and female condoms, oral contraceptives, emergency contraception, and injectables. Long-acting methods include implants and intrauterine devices (IUDs). Permanent methods include tubal ligation and female sterilization.

${ }^{2}$ For current use of any modern family planning methods, we excluded currently pregnant women and any other missing cases.

${ }^{3}$ Unmet need for family planning refers to the "Proportion of women currently not using a method and not wanting to have a baby who are at risk for pregnancy (not using a method, not currently pregnant or postpartum, fecund, sexually active in the last 30 days, and do not want a baby in the immediate future) among all women of reproductive age" (Reproductive Health Assessment Toolkit: 50). This indicator provides information on the current need for family planning among women at risk for pregnancy who wish to limit or space future births but who are not using a method.

\section{Abbreviations}

CDC: U.S. Centers for Disease Control and Prevention; CHW: Community health worker; EC: Emergency contraception; FGD: Focus Group Discussion; IAWG: Inter-agency Working Group on Reproductive Health in Crises; IEC: Information, education, and communication; IUD: Intrauterine device; MoH: Ministry of Health; SRH: Sexual and reproductive health; UNFPA: United Nations Population Fund; UNHCR: United Nations High Commissioner for Refugees; WRA: Women of reproductive age; WRC: Women Refugee Commission

\section{Acknowledgements}

In each country, the studies were led by Zinia Sultana (Bangladesh), Nassrin Farzaneh (Djibouti), Michelle Connelly (Jordan), Erin McCoy (Kenya), Sarah Knaster (Malaysia), and Neha Mankani (Uganda). The WRC would like to thank Stacy De Jesus of the CDC, Eva Lathrop of Emory University, and UNHCR staff and partners that contributed to the study. We are deeply grateful to the refugee communities that shared their valuable time and perspectives. The authors would like to acknowledge Alison Greer and Kelsea DeCosta, who contributed to the literature review, and William Axin, Yi Li, and Armani Hawes from the University of Michigan for contributing to the quantitative analysis. Shahd Osman and Lily Jacobi of the WRC, and Marian Schilperoord and Josep Vargas of UNHCR reviewed the manuscript.

\section{Funding}

The studies were funded by UNHCR; the article was supported by the John D. and Catherine T. MacArthur Foundation.

\section{Availability of data and materials}

Available upon request from the WRC.

\section{Author contributions}

MT led the development of the study design, coordinated its implementation, and drafted the manuscript. AM edited and coordinated the manuscript. PB conducted the quantitative data analysis and reported quantitative findings. NC was overall responsible for the study from UNHCR; SD followed-up on actions from the study; and SK was overall responsible for the study from the WRC. NC, SD, and SK reviewed and commented on the manuscript. All authors read and approved the final manuscript.

\section{Competing interests}

The authors declare no competing interests.

\section{Consent for publication}

Not applicable.

\section{Ethics approval and consent to participate}

The study was commission by UNHCR-Geneva, with local approval granted by the UNHCR country offices. CDC provided technical assistance, particularly for the implementation of the household survey.

\section{Publisher's Note}

Springer Nature remains neutral with regard to jurisdictional claims in published maps and institutional affiliations.

\section{Author details}

'Women's Refugee Commission, 15 W 37 Street, 9th Floor, New York, NY 10018, USA. ${ }^{2}$ Institute for Social Research, Population Studies Center, University of Michigan, 426 Thompson Street, Ann Arbor, Ml 48106, USA. ${ }^{3}$ United Nations High Commissioner for Refugees, Geneva, Switzerland.

Received: 1 November 2016 Accepted: 26 March 2017

Published online: 31 May 2017

\section{References}

1. Ama NO, Oucho JO. A multivariate approach to determinant of contraceptive use among migrants and refugees in Botswana. Journal of Family Welfare. 2007;53(2):26-42.

2. McGinn T, Austin J, Anfinson K, Amsalu R, Casey SE, Fadulalmula SI, Langston $\mathrm{A}$, et al. Family planning in conflict: results of cross-sectional baseline surveys in three African countries. Confl Health. 2011;5(11).

3. Casey SE. Evaluations of reproductive health programs in humanitarian settings: a systematic review. Confl Health. 2015;9 Suppl 1:S1.

4. Curry DW, Rattan J, Nzau JJ, Giri K. Delivering high-quality family planning services in crisis-affected settings I: program implementation. Glob Health. 2015;3(1):14-24.

5. Krause S, Williams H, Onyango MA, Sami S, Doedens W, Giga N, Stone E, Tomczyk B. Reproductive health services for Syrian refugees in Zaatri Camp and Irbid City, Hashemite Kingdom of Jordan: an evaluation of the Minimum Initial Services Package. Confl Health. 2015;9 Suppl 1:S4.

6. Ratnayake R, Degomme O, Roberts B, Spiegel P. Conflict and Health: Seven years of advancing science in humanitarian crises. Confl Health. 2014;8(7).

7. Hynes M, Sheik M, Wilson HG, Spiegel P. Reproductive health indicators and outcomes among refugee and internally displaced persons in post emergency phase camps. JAMA. 2002;288(5):595-603.

8. Van Damme W, De Brouwere V, Boelaert M, Van Lerberghe W. Effects of a refugee-assistance programme on host population in Guinea as measured by obstetric interventions. Lancet. 1998;351:1609-13.

9. Jamieson DJ, Meikle SF, Hillis SD, Mtsuko D, Mawji S, Duerr A. An evaluation of poor pregnancy outcomes among Burundian refugees in Tanzania. JAMA. 2000;283:397-402.

10. Bartlett $L A$, Jamieson DJ, Kahn T, Sultana M, Wilson HG, Duerr A. Maternal mortality among Afghan refugees in Pakistan 1999-2000. Lancet. 2002;359: $639-40$

11. Whelan A, Blogg J. 'Halfway people': Refugee views of reproductive health services. Glob Pub health. 2007;2(4):373-94.

12. McGinn T. Reproductive health of war-affected populations: what do we know? Int Fam Plan Perspect. 2000;174-180. 
13. United Nations High Commissioner for Refugees/Women's Refugee Commission. Baseline Study: Documenting Knowledge, Attitudes and Behaviours of Rohingya Refugees and the Status of Family Planning Services in UNHCR's Operation in Cox's Bazar, Bangladesh. New York (NY): WRC; 2011. Available from http://iawg.net/wp-content/uploads/2016/08/ family_planning_baseline_study_coxs_bazar_final_report-1.pdf.

14. United Nations High Commissioner for Refugees/Women's Refugee Commission. Baseline Study: Documenting Knowledge, Attitudes and Behaviours of Somali Refugees and the Status of Family Planning Services in UNHCR's Ali Addeh Site, Djibouti. New York: WRC; 2011. Available from http://www.unhcr.org/4e8c0b589.pdf.

15. United Nations High Commissioner for Refugees/Women's Refugee Commission. Baseline Study: Documenting Knowledge, Attitudes and Practices of Iraqi Refugees and the Status of Family Planning Services in UNHCR's Operations in Amman, Jordan. New York (NY): WRC; 2011. Available from http://www.unhcr.org/en-us/protection/health/4e8c0c419/baseline-studydocumenting-knowledge-attitudes-practices-iraqi-refugees.html.

16. United Nations High Commissioner for Refugees/Women's Refugee Commission. Baseline Study: Documenting Knowledge, Attitudes and Behaviours of Somali Refugees and the Status of Family Planning Services in UNHCR's Operation in Nairobi, Kenya. New York (NY): WRC; 2011. Available from http://www.unhcr.org/4e8c0cbe9.pdf.

17. United Nations High Commissioner for Refugees/Women's Refugee Commission. Baseline Study: Documenting Knowledge, Attitudes and Behaviours of Burmese Refugees and the Status of Family Planning Services in UNHCR's Operation in Kuala Lumpur, Malaysia. Available from http://www.unhcr.org/4e8c0d1c9.pdf.

18. United Nations High Commissioner for Refugees/Women's Refugee Commission Baseline Study: Documenting Knowledge, Attitudes and Practices of Refugees and the Status of Family Planning Services in UNHCR's Operations in Nakivale Refugee Settlement, Uganda. Available from http://www.unhcr.org/4e8c0da49.pdf.

19. United Nations High Commissioner for Refugees/Women's Refugee Commission. Refocusing Family Planning in Refugee Settings: Findings and Recommendations from a Multi-Country Baseline Study. New York (NY): WRC; 2011. Available from http://www.unhcr.org/4ee6142a9.pdf.

20. Division of Reproductive Health, National Center for Chronic Disease Prevention and Health Promotion, Coordinating Center for Health Promotion. Reproductive Health Assessment Toolkit for Conflict-Affected Women. Atlanta (GA): Centers for Disease Control and Prevention, Department of Health and Human Services; 2007. Available from http://www.unscn.org/layout/modules/resources/files/ ToolkitforConflictAffectedWomen.pdf.

21. Bongaarts J. A framework for analyzing the proximate determinants of fertility. Popul Dev Rev. 1978;1:105-32.

22. Bongaarts J, Potter RE. Fertility, biology, and behavior: An analysis of the proximate determinants. New York: Academic Press; 2013 Oct 22.

23. Bongaarts J, Frank $\mathrm{O}$, Lesthaeghe R. The proximate determinants of fertility in sub-Saharan Africa. Popul Dev Rev. 1984;1:511-37.

24. Bongaarts J, Mauldin WP, Phillips JF. The demographic impact of family planning programs. Stud Fam Plan. 1990;21(6):299-310.

25. Bbaale E, Mpuga P. Female education, contraceptive use, and fertility: evidence from Uganda. Consilience. Int J Sustain Dev. 2011;6(1):20-47.

26. Mason KO. The status of women: Conceptual and methodological issues in demographic studies. Sociol Forum. 1986;1:284. doi:10.1007/BF01115740.

27. Goni A, Rahman M. The impact of education and media on contraceptive use in Bangladesh: A multivariate analysis. Int J Nurs Pract. 2012;18(6):565-73.

28. Ali AA, Okud A. Factors affecting unmet need for family planning in Eastern Sudan. BMC Public Health. 2013;13(1):102.

29. MacQuarrie KL. Unmet Need for Family Planning among Young Women: Levels and Trends. DHS Comparative Reports No. 34. ICF International.: Rockville, Maryland, USA; 2014. Available from http://www.dhsprogram.com/ pubs/pdf/CR34/CR34.pdf.

30. Gedeon J, Hsue SN, Walsh M, Sietstra C, MarSan H, Foster AM Assessing the experiences of intra-uterine device users in a long-term conflict setting: a qualitative study on the Thailand-Burma border. Confl Heal. 2015;9(1):6.

31. IAWG on RH in Crises. Chapter 5: Family Planning. Inter-agency Field Manual on Reproductive Health in Humanitarian Settings: Revision for Field-testing. New York: IAWG; 2010. Available from http://iawg.net/resource/interagency-field-manual-on-reproductive-health-in-humanitarian-settings-2010/.
32. Warren E, Post N, Hossain M, Blanchet K, Roberts B. Systematic review of the evidence on the effectiveness of sexual and reproductive health interventions in humanitarian crises. BMJ Open. 2015;5(12):e008226.

33. Curry DW, Rattan J, Huang S, Noznesky E. Delivering high-quality family planning services in crisis-affected settings II: results. Glob Health. 2015;3(1):25-33.

\section{Submit your next manuscript to BioMed Central and we will help you at every step:}

- We accept pre-submission inquiries

- Our selector tool helps you to find the most relevant journal

- We provide round the clock customer support

- Convenient online submission

- Thorough peer review

- Inclusion in PubMed and all major indexing services

- Maximum visibility for your research

Submit your manuscript at www.biomedcentral.com/submit
Biomed Central 